\title{
La amplitud de coberturas de seguro para balsas de riego
}

\author{
Salinas Poch, C. (P) ponente ${ }^{1}$ \\ ${ }^{1}$ Director General Comercial de EPGSalinas, Corredores de Seguros; carlos.salinas@epgsalinas.com
}

\section{Problemática abordada}

Las balsas de riego son infraestructuras estratégicas y relevantes dentro de la actividad de una comunidad de regantes en el proceso de sondeo, captación, almacenamiento y distribución de agua para riego. Precisan, desde distintos puntos de vista, de un tratamiento particular:

- Desde el punto de vista constructivo y de explotación, con la particularidad precisa que garantice su solidez, viabilidad, sostenibilidad y seguridad, en un momento como el actual en que la escasez del recurso hídrico hace aún más notable la gestión de su almacenamiento y regulación.

- Legislativamente, tal es su importancia y peculiaridad, que en breve se espera una reglamentación expresa de seguridad de balsas, para diferenciarla de la recientemente publicada de presas y embalses. [1]

- Y como no, desde el punto de vista asegurador, se presenta el importante reto de garantizar la integridad de esta infraestructura para la continuidad de la actividad de la comunidad de regantes, ya sean por los daños que propiamente sufra la balsa, como los daños a terceros en procesos largos y complejos que comprometen el patrimonio de la entidad.

El seguro se presenta como una excelente herramienta de protección y hay que verla como una auténtica inversión a largo plazo.

\section{Descripción de la innovación}

La verdadera innovación radica en dar la mejor respuesta a las múltiples casuísticas de siniestros de daños propios e incidentes de responsabilidad civil, en todas las fases del seguro:

- Asesorar en el trabajo previo de análisis del riesgo y en la mejor opción de contratación, desde la experiencia y conocimiento de las comunidades de regantes y la agricultura de regadío

- Contar con un producto asegurador para balsas de riego, un producto especializado que tiene las correctas coberturas, definiciones y clausulado.

- Gestionar de manera eficiente el siniestro en el momento de la verdad, cuando ocurre el incidente.

\subsection{Análisis del riego}

En materia de gestión de riesgos y seguros, la tarea inicial radica en ayudar a la comunidad de regantes a identificar cuáles son los incidentes que, por su frecuencia e intensidad, pueden afectar al desarrollo de su actividad. A modo de semáforo (ver figura 1), se van evidenciando los que, por mayor frecuencia e impacto, tienen que ser transferidos al seguro (rojo y amarillo) y cuales podrían ser sumidos con los propios medios a su disposición (verde).

Esta orientación nos llevará la mejor gestión del riesgo, toma de decisiones y herramientas, entre ellas las aseguradoras. [2] 


\section{Congreso Nacional de Riegos CARTAGENA 2021}

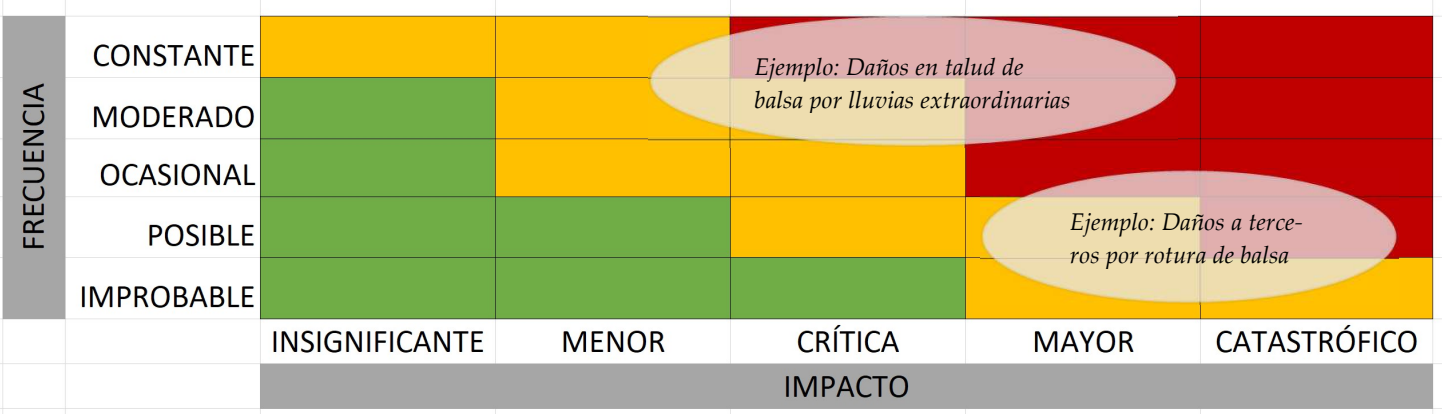

Figura 1: Ejemplo de matriz de riesgos a partir del análisis de los mismos

En balsas de riesgo, relacionando su capacidad y altura, que conllevan a su clasificación, se sitúan los distintos tipos de balsas. Cada tipo es susceptible de causar distintos daños en base a la vulnerabilidad y exposición de personas, bienes materiales y medioambientales. [2]

Según nuestra experiencia en la gestión de siniestros de balsas de riego, los de daños propios son más frecuentes en cuanto a número de siniestros, si bien los de daños a terceros (RC: responsabilidad civil) son de mayor intensidad en cuanto a pago de indemnizaciones.

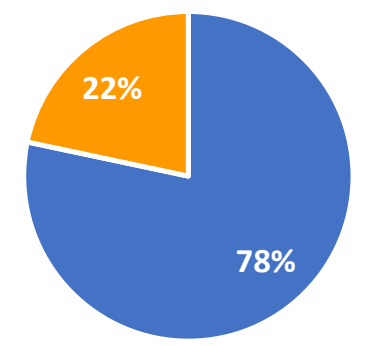

- DAÑOS PROPIOS I RC

Figura 2: Distribución según la frecuencia del tipo de siniestro de balsa de riego tramitado por EPGSalinas

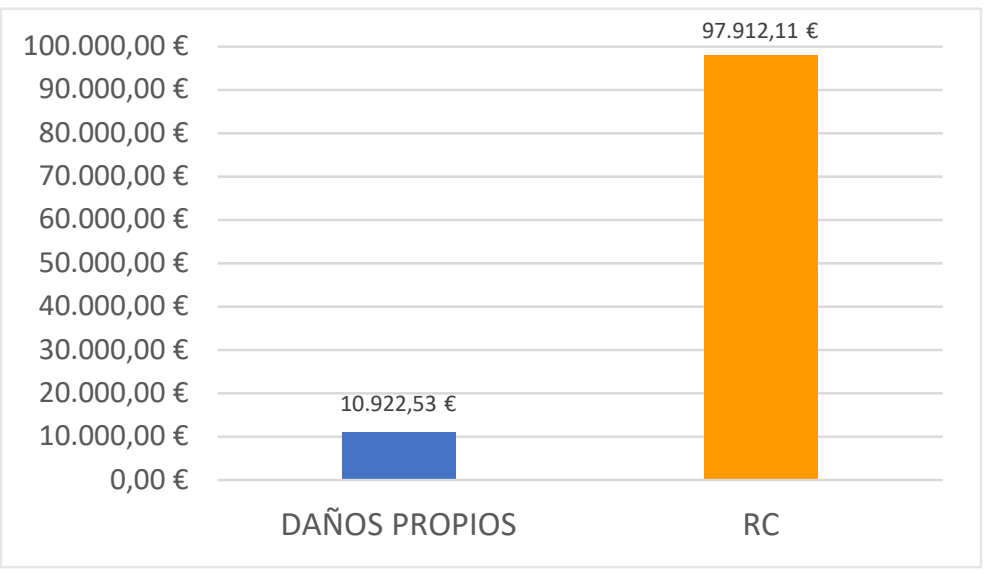

Figura 3: Coste medio de indenimización por tipo de siniestro de balsa de riego tramitado por EPGSalinas 


\subsection{Las coberturas de seguro para balsas de riego}

\subsubsection{Cobertura de daños propios para balsas de riego}

- $\quad$ Riesgo asegurado: Balsa/presa/embalse de agua para riego y todas las instalaciones relacionadas con la misma.

- Suma asegurada: El valor total de la balsa, incluida obra civil, impermeabilización, aliviadero, sistemas de regulación, cerramiento y vallado, etc.

- Coberturas: La compañía aseguradora indemniza el coste de reparación o reposición a nuevo del bien dañado o destruido (Indemnización a valor de reposición a nuevo 100\%) en caso de:

- Incendio y gastos aplicables, como desescombro y demolición, bomberos, rellenado de equipos de extinción de incendios, etc. (Aplicando su correspondiente tasa especial de Consorcio de Compensación de Seguros).

- Riesgos extraordinarios (a cargo del Consorcio de Compensación de Seguros). Acontecimientos extraordinarios cubiertos:

- Los siguientes fenómenos de la naturaleza: terremotos, maremotos, inundaciones extraordinarias (incluidas las producidas por embates de mar), erupciones volcánicas, tempestad ciclónica atípica (incluyendo los vientos extraordinarios y los tornados) y caídas de cuerpos siderales y aerolitos.

- Los ocasionados violentamente como consecuencia de terrorismo, rebelión, sedición, motín y tumulto popular.

- Hechos o actuaciones de las Fuerzas Armadas o de las Fuerzas y Cuerpos de Seguridad en tiempo de paz.

- Dato básico para cotizar: Valor de la instalación (balsa y sus equipamientos). Al ser un seguro multirriesgo, además del valor de la balsa, se facilita también el valor del resto de infraestructura y equipamientos con que cuenta la comunidad de regantes para el desarrollo de su actividad.

\subsubsection{Cobertura de responsabilidad civil para balsas de riego.}

- $\quad$ Riesgo asegurado: Titularidad, propiedad y explotación de balsa/presa/embalse de almacenamiento de agua para riego.

- $\quad$ Suma asegurada: A elección y según nivel de franquicia. $300.000 €, 600.000 €, 1.000 .000 € 1.200 .000 €$, $1.800 .000 €, 2.000 .000 €, 3.000 .000 €$

- Coberturas:

- Responsabilidad civil de explotación: Cobertura por daños originados por la propia balsa/presa/embalse, su vallado, etc., y los trabajos propios de su actividad.

- $\quad$ Responsabilidad civil patronal: Cobertura por daños personales a los empleados (y de forma subsidiaria a los empleados de contratistas o subcontratistas) como consecuencia de un accidente laboral.

- $\quad$ Responsabilidad civil subsidiaria de contratistas y subcontratistas: Cobertura por hechos derivados de la actuación de contratistas o subcontratistas y que puedan corresponder de forma subsidiaria al asegurado.

- Responsabilidad civil profesional: Cobertura por hechos derivados de la actuación del Director de Explotación y del Director del Plan de emergencia de su equipo, conforme a sus competencias, atribuciones y responsabilidades legalmente atribuidas.

- Defensa y fianzas: Cobertura para la defensa personal del asegurado por abogados y procuradores en procedimientos civiles y criminales, la constitución de fianzas, así como el pago de gastos judiciales.

- $\quad$ Dato básico para cotizar: capacidad de la balsa (en m3). 
Adicionalmente, el titular de la balsa conoce si está clasificada, ya que como hemos expuesto anteriormente, es un factor relevante para determinar el grado de riesgo de la balsa en función de su capacidad y altura.

- No requieren clasificación. Altura inferior a 5 metros o capacidad inferior a $100.000 \mathrm{~m} 3$

- Requieren clasificación. Altura superior a 5 metros y capacidad superior a 100.000 m3.

\section{Clasificación:}

- Tipo A. Aquellas cuya rotura o funcionamiento incorrecto puede afectar gravemente a núcleos urbanos o a servicios esenciales, así como producir daños materiales o medioambientales muy importantes.

- Tipo B. Aquellas cuya rotura o funcionamiento incorrecto puede afectar a un número reducido de viviendas u ocasionar daños materiales o medioambientales importantes.

- Tipo C. Aquellas cuya rotura o funcionamiento incorrecto puede producir daños materiales de moderada importancia y solo incidentalmente pérdidas de vida humanas.

Pendientes de Clasificar. Aquellas balsas que están obligadas según sus características a ser clasificadas pero aún no tiene asignada una clasificación.

\subsubsection{Cobertura de responsabilidad medioambiental para balsas de riego}

- $\quad$ Riesgo asegurado: Titularidad, propiedad y explotación de balsa/presa/embalse de almacenamiento de agua para riego.

- Suma asegurada: Límite independiente para responsabilidad civil general y para responsabilidad medioambiental y por contaminación, esta última por cada una de las balsas.

- Coberturas: La compañía aseguradora garantiza el pago de indemnizaciones al asegurado frente a cualquier pérdida (indemnizaciones a terceros, gastos de limpieza, gastos legales, gastos de aminoración) inesperada e involuntaria que estuviera legalmente obligado a pagar como resultado de reclamaciones o pérdidas resultantes de:

- Daños a los recursos naturales incluyendo los gastos necesarios para proceder a la reparación del medioambiente dañado en sus tres grados de reparación conforme a la Ley 26 / 2007, por contaminación o por cualquier otra causa derivada de la actividad desarrollada.

Por daños a los recursos naturales se entiende el daño físico o la destrucción real de agua, suelo o especies protegidas o hábitats naturales respecto de los cuales el asegurado es legalmente responsable conforme a la Directiva de la Unión Europea 2004/35/CE sobre responsabilidad medioambiental y/o cualquier legislación local equivalente y en concreto la Ley 26/2007 de Responsabilidad por Daños al Medioambiente.

- Costes de prevención. Costes de medidas tomadas para prevenir la inminente ocurrencia del daño.

- Defensa y fianzas. Cobertura para la defensa personal del asegurado por abogados y procuradores en procedimientos civiles y criminales, la constitución de fianzas, así como el pago de gastos judiciales.

- $\quad$ Dato básico para cotizar: capacidad de la balsa (en m3).

Un factor relevante para determinar el grado de riesgo medioambiental es la existencia espacios protegidos en la zona geográfica donde se ubique la balsa/presa/embalse, como: 


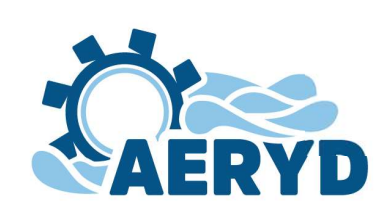

\section{Congreso Nacional de Riegos CARTAGENA 2021}

- ZEPA: Zona de Especial Protección para las Aves. (Figura 2).

- LIC: Lugar de Interés Comunitario. (Figura 2)

- PEIN: Espacio natural protegido incluido en el Plan de Espacios de Interés Natural. (Figura 3).

- HUMEDAL: Zona de tierras, generalmente planas, en la que la superficie se inunda permanente o intermitentemente con interés biológico. (Figura 4)

- ZONA PROTEGIDA: Zona protegida por otra causa no descrita en los apartados anteriores.

- ZONA PIV: Existencia de viviendas, polígono industrial y/o infraestructuras de servicios esenciales en un radio de 150 metros.

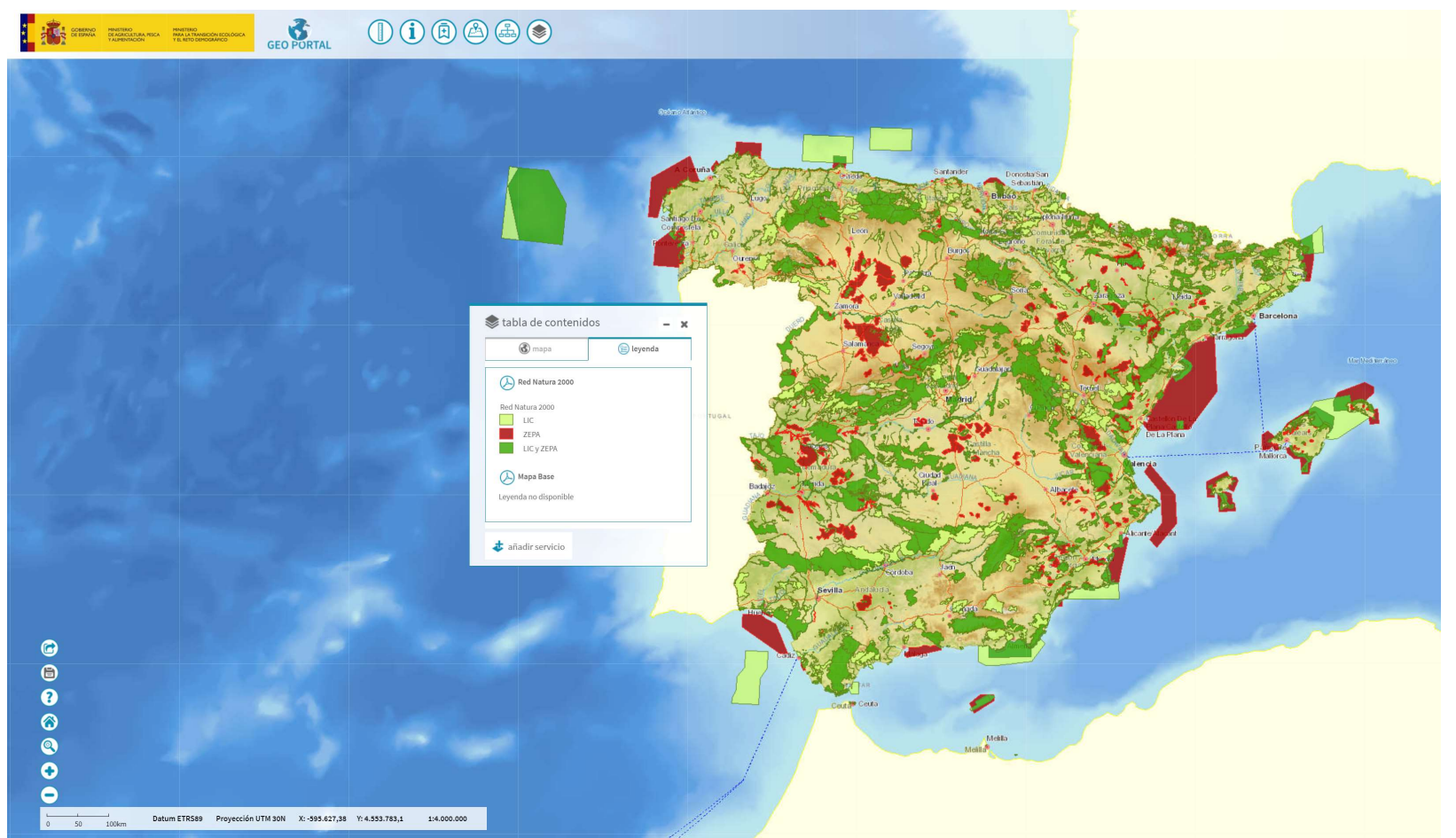

Figura 4: zonas LIC, ZEPA, LIC y ZEPA según Red Natura 2000. Geoportal del Ministerio Agricultura, Pesa y

Alimentación. https://sig.mapama.gob.es/geoportal/ 


\section{IAERYD CARTAGENA 2021

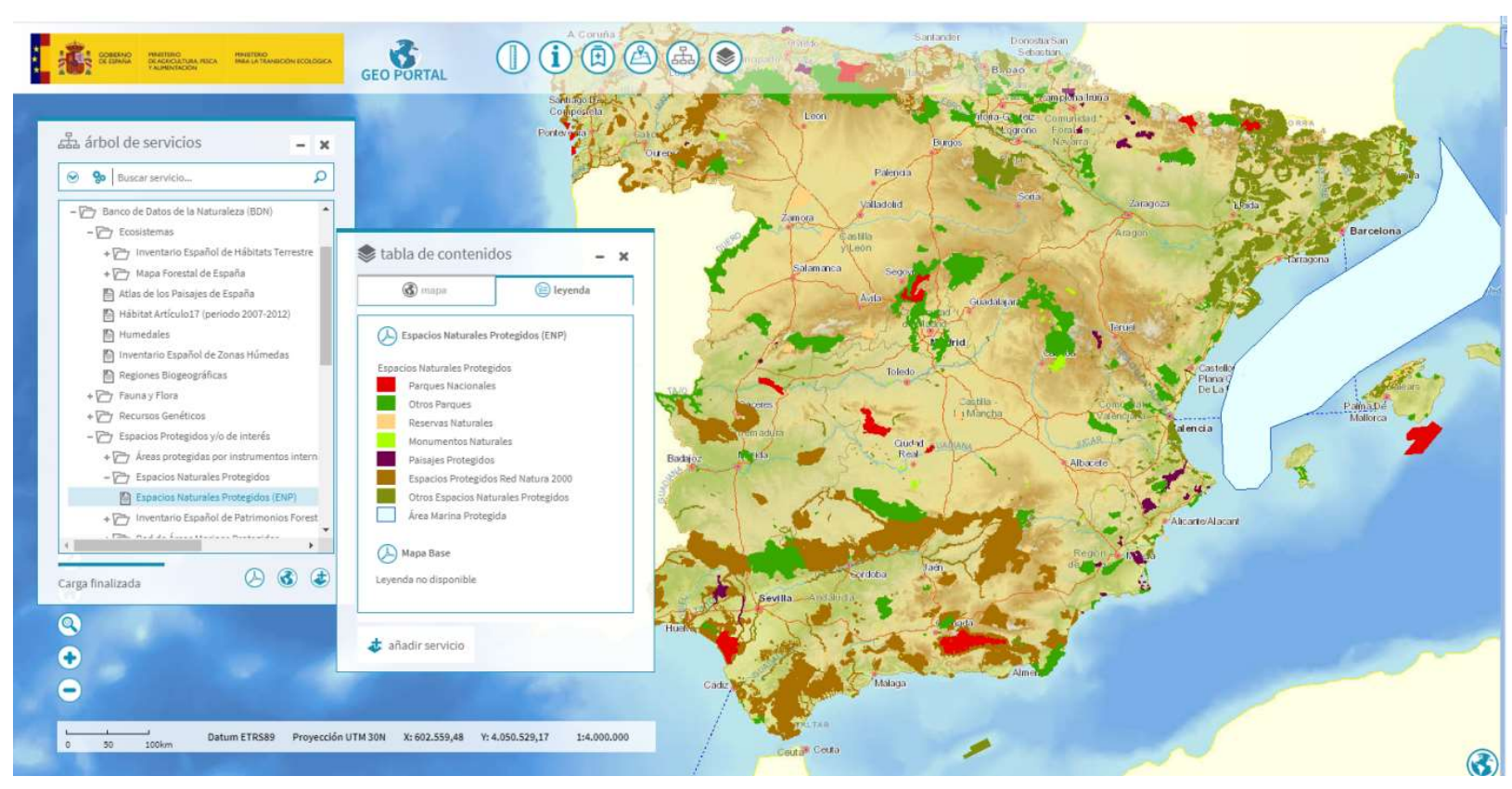

Figura 5: zonas Espacios Naturales Protegidos según Banco de Datos de la Naturaleza. Geoportal del Ministerio Agricultura, Pesca y Alimentación. https://sig.mapama.gob.es/geoportal/

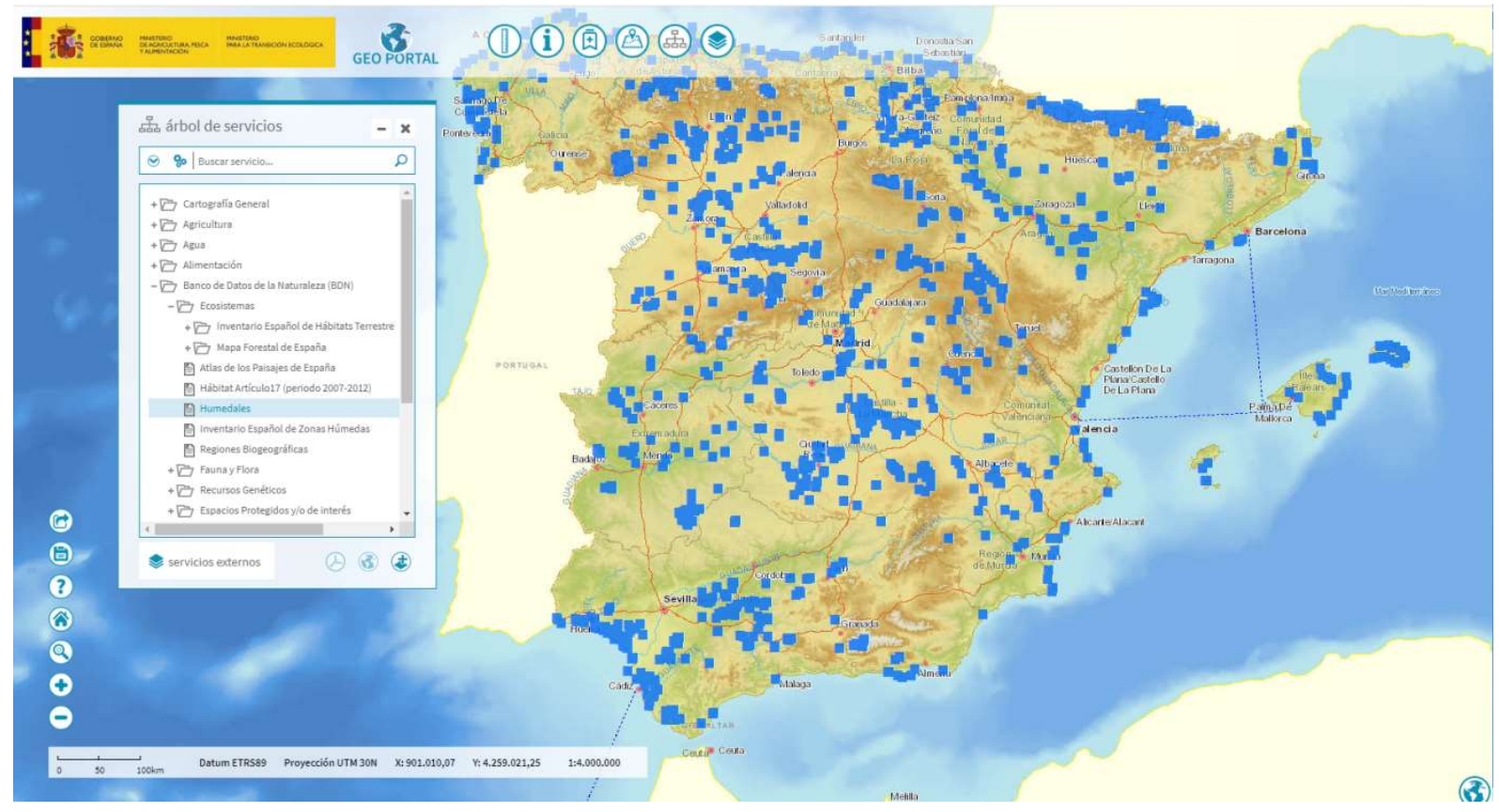

Figura 6: zonas Humedales según Banco de Datos de la Naturaleza. Geoportal del Ministerio Agricultura, Pesca y Alimentación. https://sig.mapama.gob.es/geoportal/ 


\section{Congreso Nacional de Riegos CARTAGENA 2021}

\subsection{El siniestro.}

Cuando ocurre un siniestro, siendo un momento clave en la vida de la póliza de seguro, es fundamental seguir una serie de pasos y plazos establecidos, siempre de la mano del mediador de seguros de la póliza, que acompañará a la comunidad de regantes en la atención inmediata del siniestro, su tramitación y la mejor consecución del mismo. Son relevantes las tareas de lectura e interpretación de garantías y clausulado de la póliza, seguimiento de informes periciales, y otras labores propias como interlocutor entre el cliente y la aseguradora, siempre en defensa del asegurado y en comunicación directa y especializada.

\subsubsection{Caso real 1:}

- Causa y descripción: Rotura de balsa de riego con una brecha de 5-6 metros por la que se produce la pérdida de $180.000 \mathrm{~m} 3$ de agua almacenada (en una hora aproximadamente se produce el vaciado de la misma).

- Daños provocados: La onda hidráulica provoca daños materiales importantes a terceros a lo largo de $4 \mathrm{~km}$, con una superficie total afectada de 27,53 has de:

- Cultivos

- Infraestructuras

- Daños al Dominio Público Hidráulico (cauce de un arroyo)

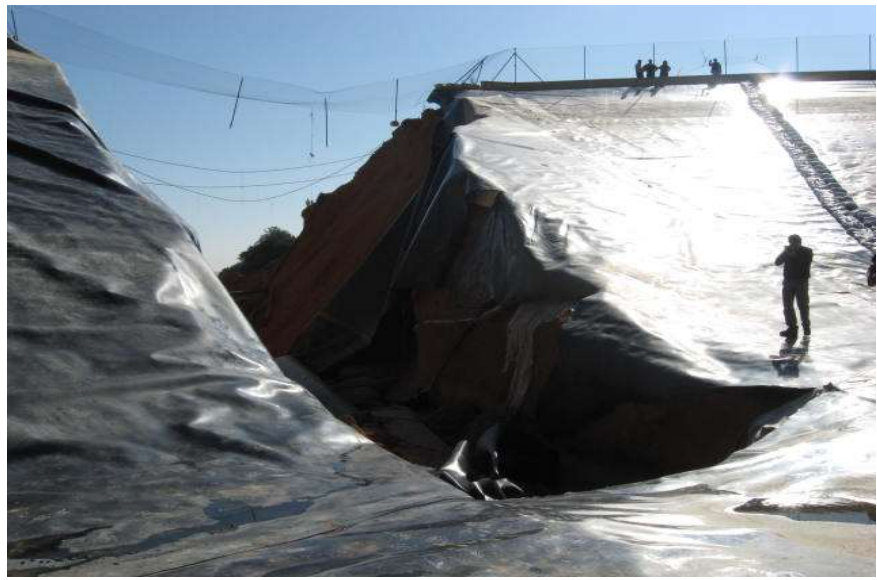

Figura 7: imagen de la brecha abierta en la balsa de riego

\subsubsection{Caso real 2:}

- Causa y descripción: La avería del sistema automatizado de regulación del trasvase de agua de una balsa de $450.000 \mathrm{~m} 3$ a la de $80.000 \mathrm{~m} 3$ (sonda de presión y boya de control de nivel de agua) produce el desbordamiento de la balsa de capacidad de $80.000 \mathrm{~m} 3$, por encima del rebosadero.

- Daños provocados: Daños a terceros en fincas colindantes de dos comuneros, con arrastre de tierras.

\subsubsection{Caso real 3:}

- Causa y descripción: Intensas precipitaciones provocan que el agua se infiltre por el terreno y además, que descienda por la pendiente en forma de escorrentía, produciendo disgregación de material y movimientos superficiales. 


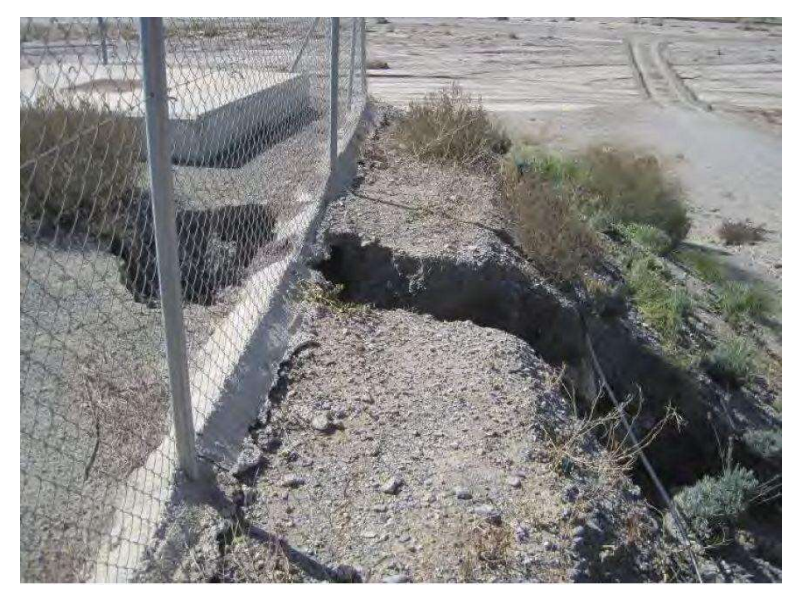

Figura 8: socavón en coronación de balsa y pérdida de pendiente

- Daños provocados: Daños propios en taludes y coronación de las balsas (perdida de pendiente y socavones) por la garantía consorciable de inundación extraordinaria.

\subsubsection{Tipos de siniestros.}

Los siniestros de balsas de riego, cuyas casuísticas y circunstancias son múltiples, podríamos clasificarlos en:

1. Siniestros de daños activos, que provoca la balsa propiamente dicha, hacia el exterior. Ejemplo: por rotura o desbordamiento de la balsa.

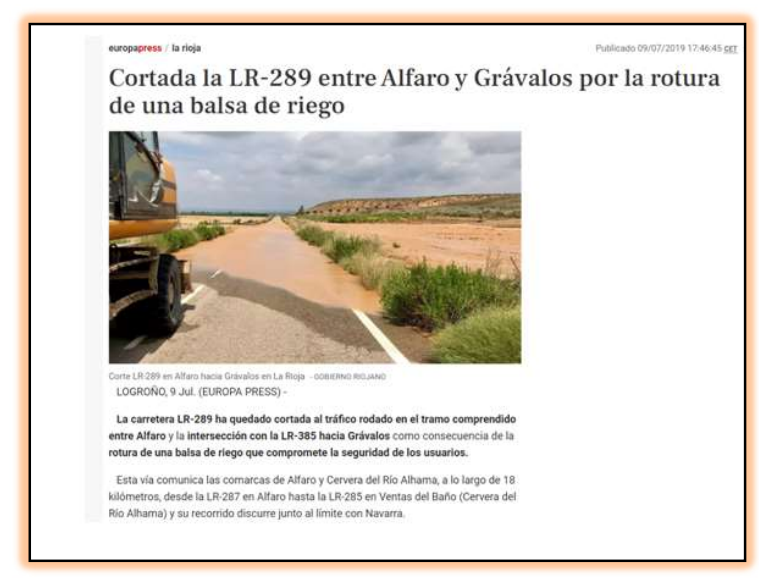

Figura 9: Cortada la LR-289 entre Alfaro y Grávalos por la rotura de una balsa de riego

(9 de julio de 2019). Europapress, La Rioja. Recuperado de http://www.europapress.es/

2. Siniestros de daños pasivos, en que ningún hecho fortuito y accidental de la balsa produce el daño; es decir, la propia balsa no causa el daño. Ejemplo: personas ahogadas en la balsa. 


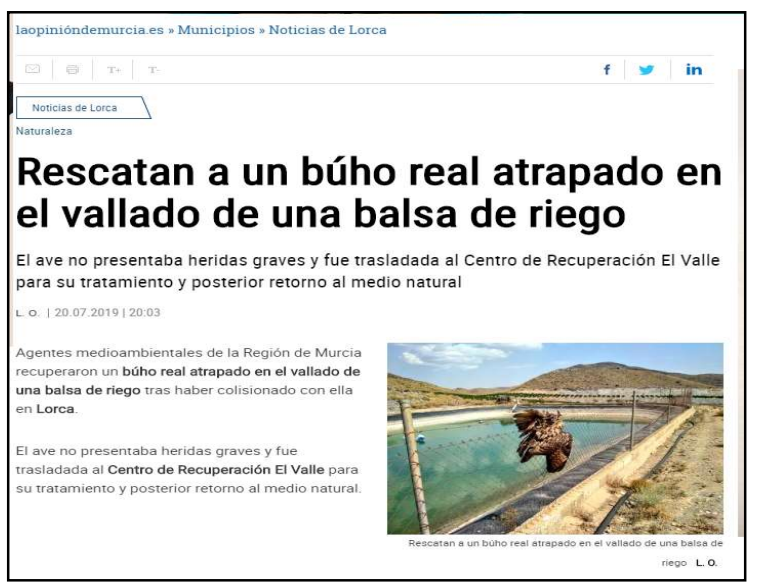

Figura 10: L.O. Rescatan a un búho real atrapado en el vallado de una balsa de riego (20 de julio de 2019). La Opinión de Murcia, Municipios. Recuperado de http://www.laopiniondemurcia.es/

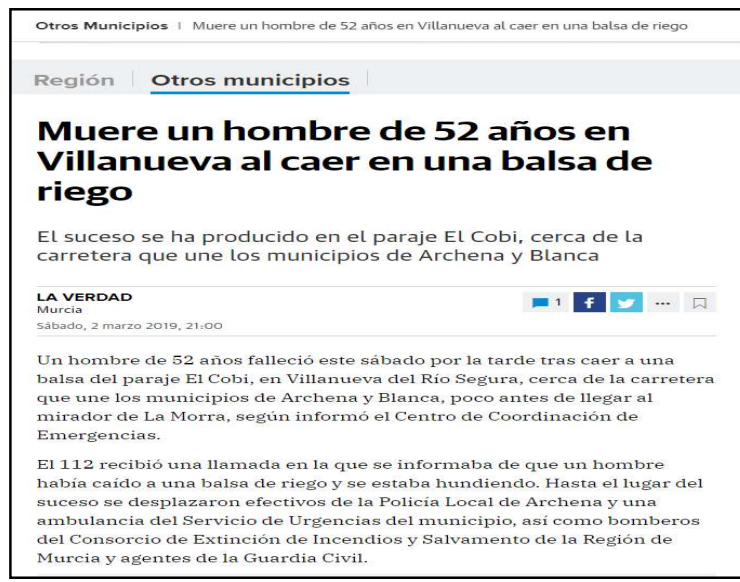

Figura 11: Muere un hombre de 52 años en Villanueva al caer en una balsa de riego (2 de marzo de 2019). La Verdad, Murcia. Recuperado de http://www.laverdad.es/

\section{Resultados obtenidos en ensayo o en explotación comercial.}

El éxito del seguro de balsas radica en ser único en el mercado asegurador, específico para este riesgo en concreto. Nuestra especialización se basa en más de 35 años asegurando comunidades de regantes, a través de un completo programa de seguros, entre los que se encuentra el de balsas.

Somos referentes en el aseguramiento del sector de la agricultura de regadío, contando en la actualidad con más de 400 comunidades de regantes que son clientes de EPGSalinas. Son ya más de 500 balsas aseguradas por todo el territorio español, que representan en torno a $85 \mathrm{hm} 3$ de capacidad de almacenamiento de agua en balsas aseguradas, con una media alrededor de $170.000 \mathrm{~m} 3$ por balsa y un promedio de 7,5 metros de altura. Las balsas clasificadas del tipo A, representan el $33 \%$ del total de las aseguradas clasificadas.

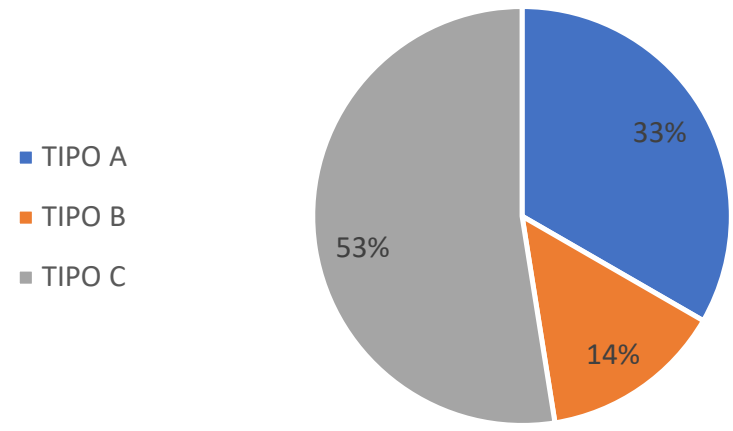

Figura 12: Distribución de la tipología de balsas clasificadas aseguradas a través de EPGSalinas 


\section{Congreso Nacional de Riegos CARTAGENA 2021}

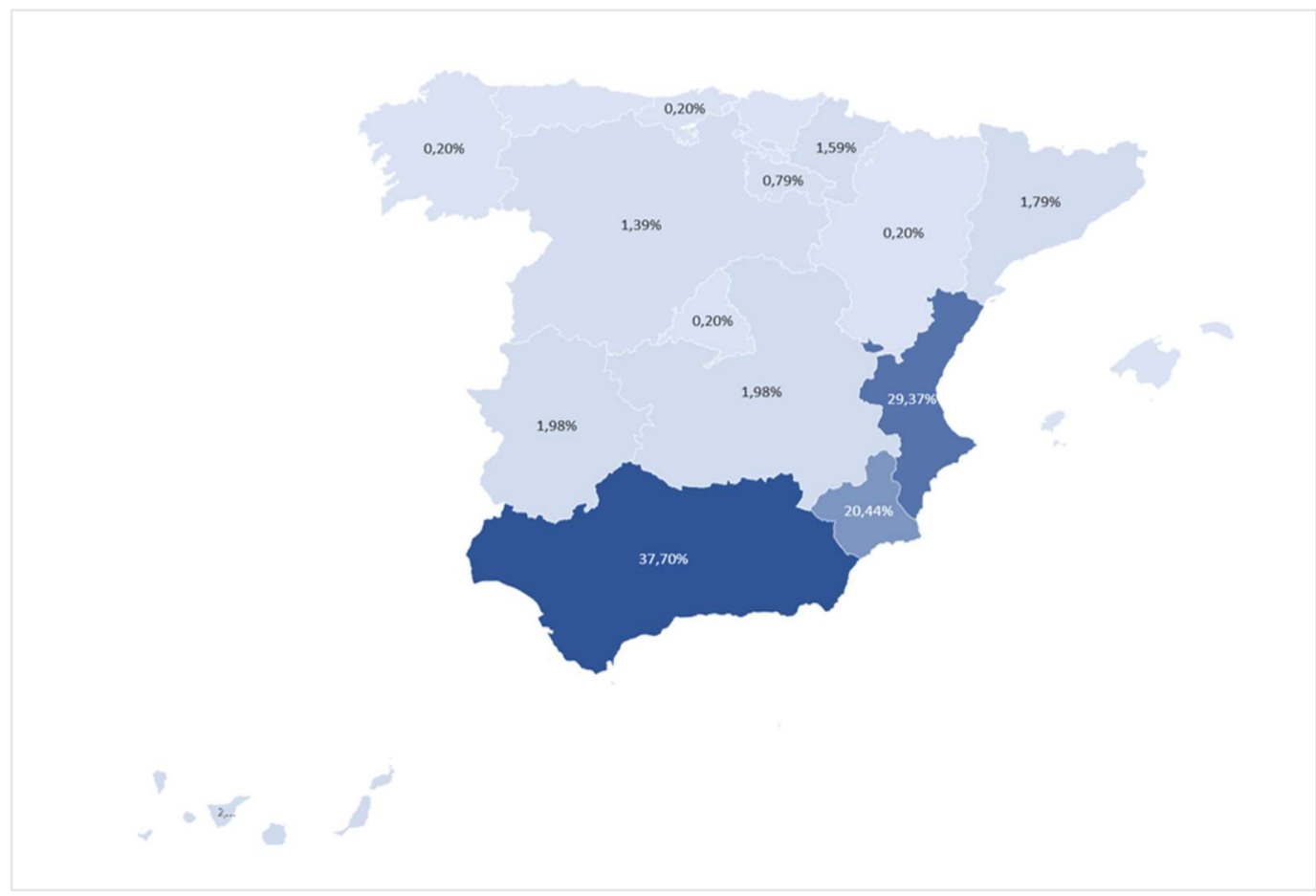

Figura 13: Distribución de las balsas aseguradas a través de EPGSalinas

\section{Conclusiones}

1. Hay que ser consciente de que a pesar del exhaustivo control de la seguridad y mantenimiento de las balsas de riego, los siniestros de balsas por rotura o mal funciomamiento suceden, accidental y fortuitamente, y hay que estar preparados.

2. Los siniestros de responsabilidad civil y medioambiental son muy diferentes a los siniestros de daños propios, con particularidades como temporalidad, complejidad y ponen en juego el patrimonio y la reputación.

3. Hay que estar bien asegurados: la importancia de encontrar seguros especializados.

4. Además de estar bien asegurados, es fundamental estar bien asesorados. Es relevante la labor del corredor de seguros, en continua innovación en cuanto a soluciones aseguradoras y servicios.

5. Visión $360^{\circ}$ de los riesgos de las comunidades de regantes: todos los riesgos asegurados bajo un programa específico de seguros.

\section{Referencias}

1. De Cea, Juan Carlos (Dirección General del Agua MITERD, Comisión de normas de grandes presas, experto de la CR en seguridad de infraestructuras). Evolución de la normativa en seguridad de balsas de riego. Jornada sobre la Gestión de la Seguridad en Balsas de Riego. Madrid, 2021

2. Espejo Almodóvar, Fernando (profesor titular de la Universidad de Salamanca). Propuestas de clasificación de balsas. Aplicación práctica del marco normativo. Jornada sobre la Gestión de la Seguridad en Balsas de Riego. Madrid, 2021 